\title{
Effects of Cadmium on the Impedance Locus of the Abdominal Skin of the Bullfrog (Rana catesbeiana)
}

\author{
Akira Arita, Makoto Takada, and Hideo Hayashi \\ Department of Physiology, Saitama Medical School, Moroyama, Iruma-gun, \\ Saitama, 350-04 Japan
}

Summary An impedance locus consisting of two superimposed semicircular arcs was revealed on the abdominal skin of the bullfrog. The decrease of skin resistance upon epidermal application of $\mathrm{Cd}(2 \mathrm{~mm})$, which was related to $\mathrm{Na}$ active transport, proved to be due solely to the reduction in the size of the high frequency arc.

We have investigated the effects of cadmium $(\mathrm{Cd})$ on the sodium $(\mathrm{Na})$ active transport of frog skin, and have found that epidermal application of $2 \mathrm{mM} \mathrm{Cd}$ increased the short circuit current (SCC) and the potential difference across the skin (PD), but decreased the skin resistance $\left(R_{\mathrm{M}}\right)$ (HAYASHI et al., 1977). The aim of this paper is to elucidate the effects of $\mathrm{Cd}$ action in respect to the impedance.

Upon analysis of the electrical equivalent circuit of some biomembranes, they have been found to consist of two membrane components: FALK and FATT (1964) discussed the impedance of frog muscle in accordance with a parallel and a series $\mathrm{RC}$ circuit in parallel which might represent the surface membrane and sarcoplasmic reticulum. Though a single semicircular arc of impedance locus was observed in frog skin which was soaked in Cl-Ringer's solution (BROWN and Kastella, 1965), SMith (1971) found the impedance locus in the frog skin consisted of two semicircular arcs in both $\mathrm{Cl}$ - and $\mathrm{SO}_{4}$-Ringer's solution, and called them as the low frequency arc and the high frequency arc, respectively. These two arcs were expressed as the model of two membrane components in series. From experiments in which the Na concentration was diluted on either side, Smith attributed the high frequency arc to the outward-facing membrane.

We proposed the hypothesis that $\mathrm{Cd}$ may exert its effect on the outer barrier of frog skin. This assumption was examined by measuring the impedance locus of the intact skin as well as the isolated epidermis.

Experiments were carried out in $\mathrm{SO}_{4}$-Ringer's solution by using Ussing-type lucite chambers with an exposed area of $0.79 \mathrm{~cm}^{2}$ (HAYASH et al., 1977) at room temperature $\left(19-21^{\circ} \mathrm{C}\right)$. The composition of $\mathrm{SO}_{4}$-Ringer's solution was as follows

Received for publication May 25, 1979

有田 彰, 高田真理, 林 秀生 
(in $\mathrm{mM}$ ): $\mathrm{Na}_{2} \mathrm{SO}_{4} 55, \mathrm{~K}_{2} \mathrm{SO}_{4} 1, \mathrm{Ca}$ gluconate 1 , glucose 10 , sucrose 60 and Tris$\mathrm{H}_{2} \mathrm{SO}_{4}$ buffer 10 ( $\mathrm{pH} \mathrm{7.2).} \mathrm{The} \mathrm{impedance} \mathrm{measurement} \mathrm{was} \mathrm{made} \mathrm{under} \mathrm{voltage}$ clamp conditions (gain: $\times 1,000$ ) after the PD, SCC and $R_{\mathrm{M}}$ became steady (about 1-4 hr after the start of the experiment). The DC holding skin potential was the PD under unclamped conditions just prior to the measurement. The PD was recorded differentially with a pair of calomel electrodes and a DC preamplifier (gain: $\times 1, Z_{\mathrm{i}}: 1 \mathrm{M} \Omega$ ). The current was supplied through an $\mathrm{Ag}-\mathrm{AgCl}$ electrode, while another $\mathrm{Ag}-\mathrm{AgCl}$ current electrode was connected to a current-voltage converter for recording the current signal. Both the voltage and current signals (about two cycles at each frequency) were stored simultaneously in a digital memory. The readout from the memory was displayed on an X-Y recorder as a Lissajous' figure. The complex impedance $(\dot{Z})$ of the skin is defined as $\dot{Z}=|Z| \mathrm{e}^{j \theta}$, where $|Z|$ and $\theta$ are the amplitude and the phase angle of the complex impedance, respectively. $|Z|$ is given as the ratio of amplitude of the voltage signal to the current, and $\theta$ is given as the phase difference between the voltage signal and the current. $|Z|$ and $\theta$ were calculated to be in the range of $0.1 \mathrm{~Hz}-1 \mathrm{kHz}$ from the Lissajous' figure. The impedance of Ringer's solution in chambers without preparation was as follows: $|Z|$ was about $160 \Omega \cdot \mathrm{cm}^{2}$ and $\theta$ was less than $4^{\circ}$. The amplitude of superimposed sinusoidal voltage was usually $20 \mathrm{mV}_{\mathrm{p} \text {-p }}$. The currentvoltage relation in frog skin was linear in the range of 2 to $20 \mathrm{mV}_{\mathrm{p} \text {-p }}$, i.e., a voltagedependent change in resistance ( $c f$. FINKELSTEIN and MAURO, 1963) was never observed in this small potential change (HAYASHI et al., 1978). Linearity of the $I-V$ relation was also observed even though the PD was altered by application of $\mathrm{Cd}$.

The impedance locus of the control skin is shown in Fig. 1 (solid line). The impedance locus of this preparation was divided into two semicircular parts: a low frequency arc and a high frequency one. The crossover frequency was $2 \mathrm{~Hz}$ (ranging from 2 to $10 \mathrm{~Hz}, n=13$ ), and the DC resistance was $3.29 \mathrm{k} \Omega \cdot \mathrm{cm}^{2}[3.25 \pm$ $0.64 \mathrm{k} \Omega \cdot \mathrm{cm}^{2}$ (mean \pm standard error, $n=13$ )]. These values agreed very closely with Smith's data in normal $\mathrm{SO}_{4}$-Ringer's solution. In some cases, the impedance

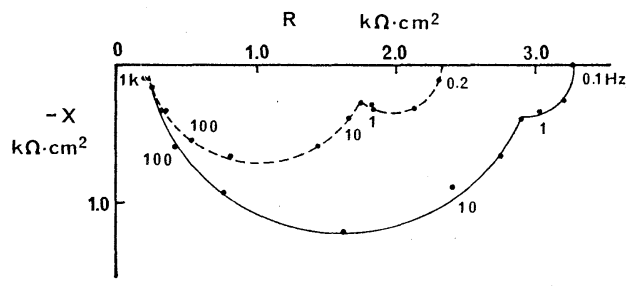

Fig. 1. Impedance loci of the abdominal skin of the bullfrog. The impedance was measured in $\mathrm{SO}_{4}$-Ringer's solution before (solid line), and after (dotted line) epidermal application of $2 \mathrm{~mm} \mathrm{Cd}$ for $20 \mathrm{~min}$. Horizontal axis $(R)$ : real part of impedances $\left(\mathrm{k} \Omega \cdot \mathrm{cm}^{2}\right)$. Vertical axis $(-X)$ : imaginary part of impedance $\left(\mathrm{k} \Omega \cdot \mathrm{cm}^{2}\right)$. The impedances were measured at frequencies of 1-2-5 series. The impedance at $0.2 \mathrm{~Hz}$ in control skin was omitted. The impedance locus of the figure was not compensated for by the impedance of the chamber and solution $\left(160 \Omega \cdot \mathrm{cm}^{2}\right)$. 

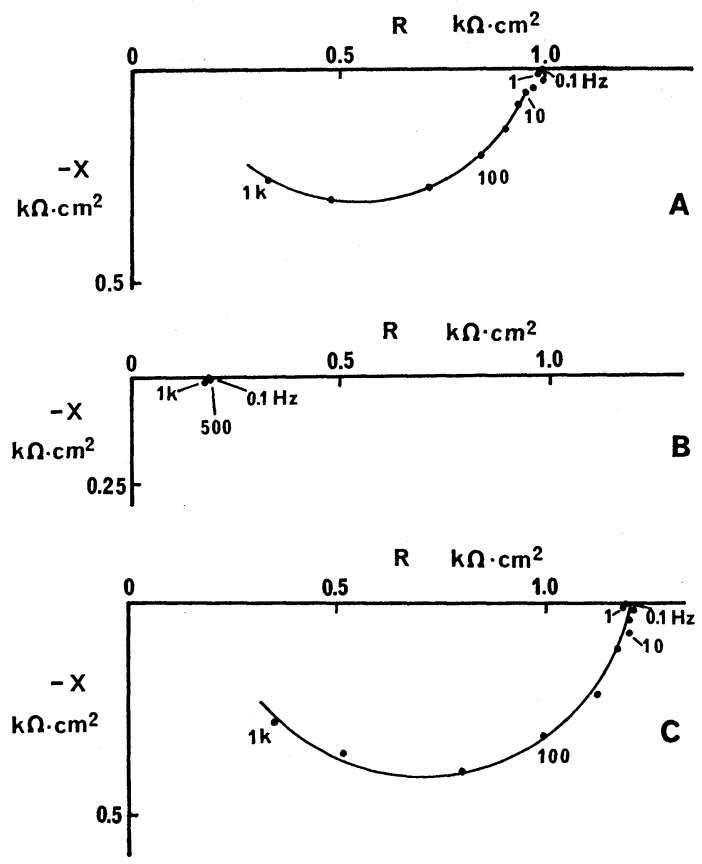

Fig. 2. Impedance loci of isolated preparations of skin which were obtained by collagenase treatment $(0.1 \mathrm{mg} / \mathrm{ml})$ for $15 \mathrm{hr}$. A: isolated epidermis. B: isolated dermis. C: whole frog skin treated with collagenase. The impedances were measured at frequencies of 1-2-5 series, but impedances at 0.2 and $0.5 \mathrm{~Hz}$ were omitted. In $\mathrm{B}$, the impedances from 0.1 to $500 \mathrm{~Hz}$ were so close together that they look like one point in the figure. Other explanations are the same as for Fig. 1.

locus did not show a clearcut separation into the two arcs. The dotted line in Fig. 1 illustrates the impedance locus of frog skin treated with epidermal $2 \mathrm{~mm}$ $\mathrm{Cd}$ for $20 \mathrm{~min}$. Cadmium increased the SCC by $22.6 \%$ in this case. The high frequency arc of the impedance locus was reduced in its size $(57.5 \%$ of the control skin, in diameter), while the low frequency arc shifted to the left with little change in size (the difference from the control skin was less than $5 \%$ in diameter). In other words, the length of the vector of the high frequency arc was reduced, whereas that of the low frequency arc did not change appreciably.

We examined the impedance of the isolated epidermis and dermis in order to test which part of the skin accounted for the impedance locus. The epidermis and dermis were treated with collagenase. Collagenase $(0.1 \mathrm{mg} / \mathrm{ml})$ was applied to the dermal side for $15 \mathrm{hr}$ to obtain isolated epidermis, while the enzyme was applied to the epidermal side for $15 \mathrm{hr}$ to obtain isolated dermis. The dermis and the epidermis were completely separated by microdissection after the collagenase treatment. The structure of the epidermis was well maintained (Takada and Hayashi, in press). Figure 2 illustrates the impedance loci of the enzyme- 
treated preparations. The impedance locus of the isolated epidermis showed a semicircular pattern (Fig. 2A). The characteristic frequencies of the isolated epidermis and the intact skin, which were defined as the frequencies of maximum reactance, were about 300 and $20 \mathrm{~Hz}$, respectively. The size of the impedance locus of the isolated epidermis was smaller $(30.1 \%$ in diameter of the intact skin). The low frequency arc in the impedance locus of the isolated epidermis was small, but discernible. Figure $2 \mathrm{~B}$ indicates the impedance locus of the isolated dermis. The distinctive feature of the isolated dermis was that the impedance locus did not form semicircles and converged at the same point. $|Z|$ of the isolated dermis did not change and the $\theta$ was nearly zero degrees; i.e., the impedance of the isolated dermis was purely resistive. Figure $2 \mathrm{C}$ represents the impedance locus of the whole skin which is treated with collagenase from the dermal side of the skin, but is not separated into epidermis and dermis. The impedance locus of the enzymetreated whole skin showed a figure similar to the isolated epidermis (Fig. 2A); the size of the impedance locus was almost the same, but the locus was shifted to the right. It is likely that the impedance locus of the collagenase-treated whole skin (Fig. 2C) is the summation of vectors of the impedance of the isolated epidermis (Fig. 2A) and the isolated dermis (Fig. 2B). Since the only difference in the procedures for obtaining the preparations in the collagenase-treated whole skin (Fig. 2C) and the isolated epidermis (Fig. 2A) was in the surgical separation, this separation does not seem to affect the shape of the impedance locus. Therefore, the two semicircular arcs of the intact skin were found to be located in the epidermis but not in the dermis. The difference between the impedance loci of the intact skin (Fig. 1, solid line) and the collagenase-treated preparation (Fig. 2A) may not be due to the surgical operation separating the dermis and the epidermis, but to the destructive action on the membrane by the enzyme.

From these experiments, we concluded that the $\mathrm{Cd}$ reduced the size of the high frequency arc of the impedance locus only in the epidermis. On the other hand, our previous papers disclosed that the Cd-induced decrease in $R_{\mathrm{M}}$ mainly corresponded to the decrease in resistance of the outer facing skin (HAYASHI et al., 1977, 1978). The distribution of epidermally-applied Cd suggested the outside barrier for $\mathrm{Cd}$ existed between the stratum corneum and stratum granulosum (TAKADA and HAYASHI, 1978). Considering the data in the present and the previous papers, we deduced that the high frequency arc of the impedance locus in frog skin might represent one of the characteristics of the outside barrier in the epidermis. Measurement of the skin impedance locus would provide a useful tool for investigating $\mathrm{Cd}$ action on $\mathrm{Na}$ transport.

This work was supported in part by Grant-in-Aid for Encouragement of Young Scientist.

\section{REFERENCES}

Brown, A. C. and Kastella, K. G. (1965) The AC impedance of frog skin and its relation to 
active transport. Biophys. J., 5: 591-606.

FALK, G. and FATT, P. (1964) Linear electrical properties of striated muscle fibres observed with intracellular electrodes. Proc. R. Soc., Ser. B., 160: 69-123.

Finkelstern, A. and MaUro, A. (1963) Equivalent circuit as related to ionic systems. Biophys. $J ., 3: 215-237$.

HaYashi, H., TAKaDa, M., and ARITA, A. (1977) Effects of cadmium on the active transport of sodium by the abdominal skin of a bullfrog (Rana catesbeiana). Jpn. J. Physiol., 27: $337-352$.

Hayashi, H., Takada, M., and ARITA, A. (1978) Cadmium-induced decrease in the outer facing skin resistance of a bullfrog (Rana catesbeiana). Jpn. J. Physiol., 28: 63-73.

Smith, P. G. (1971) The low-frequency electrical impedance of the isolated frog skin. Acta Physiol. Scand., 81: 355-366.

TAKADA, M. and HAYASH, H. (1978) Distribution of cadmium in the cross-section of cadmium treated abdominal skin of bullfrog. Proc. Jpn. Acad., 54B: 369-374. 